
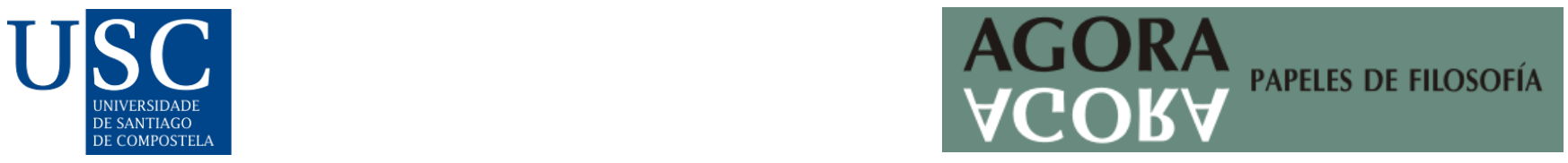

Agora. Papeles de Filosofía, 41(1), 2022. ISSN-e: 2174-3347

https://doi.org/10.15304/agora.41.1.7488

Estudios

\title{
HACIA UNA TEORÍA FEMINISTA DEL ESTADO. EL ESTADO DE LOS CUIDADOS ${ }^{1}$
}

\author{
Jacinta Gorriti ${ }^{1} \mathbb{D}$, Roque Farrán ${ }^{2} \mathbb{D}$ \\ ${ }^{1}$ Universidad Nacional de Córdoba, Argentina Consejo Nacional de Investigaciones Científicas y Técnicas, Argentina \\ ${ }^{2}$ Universidad Nacional de Córdoba, Argentina Consejo Nacional de Investigaciones Científicas y Técnicas, Argentina
}

Recibido: 09/02/2021; Aceptado: 30/06/2021

\section{Resumen}

En este texto exploramos y presentamos algunos elementos que nos permiten considerar la elaboración de una teoría feminista del Estado. Partimos de una perspectiva filosófica materialista que nos brinda un marco amplio y riguroso de indagación, que incluye una consideración por la tópica social compleja en la que se inscriben nuestras prácticas y una especial atención sobre la dinámica de los afectos que nos orientan en ellas. En función de esta perspectiva, proponemos el concepto de Estado de los cuidados. La lógica de los cuidados a la que nos referimos aquí no se limita al problema de la reproducción social sino que atraviesa el conjunto de instancias y de prácticas e involucra en simultáneo un modo de conocer, un modo de ser y un modo de constituirse a sí mismo.

Palabras clave: Estado; materialismo; cuidados; afectos; neoliberalismo.

\begin{abstract}
In this text we explore and present some elements that allow us to consider the elaboration of a feminist theory of the State. In principle, it is about starting from a materialistic philosophical perspective that provides us with a broad and rigorous framework for inquiry, which includes a consideration of the complex social topic in which our practices are inscribed and a special attention to the dynamics of affects that guide us in them. Based on this perspective, we propose the concept of State of care. The logic of care to which we refer here is not limited to the problem of social reproduction but crosses the set of instances and practices, and simultaneously involves a way of knowing, a way of being and a way of constituting oneself.
\end{abstract}

Keywords: State; materialism; care; affection; neoliberalism.

\section{FEMINISMO(S) SIVE MATERIALISMO(S)}

Desde hace un tiempo nos preguntamos si es posible formular una teoría feminista del Estado. Es decir, una teoría que no solo retome las principales categorías que conforman una especie de decálogo de las luchas feministas actuales (transversalidad, pluralismo, diversidad, cuidado, 
cuerpo, deseo), sino que además reelabore a la luz de un marco teórico o filosófico sistemático más amplio estos conceptos, para pensar al Estado en toda su complejidad y estricta singularidad. Sin duda, la pregunta por el Estado no es nueva para los feminismos. En la larga historia de las luchas feministas, que tiene en la crítica de las formas estatales y en la interpelación al Estado dos pilares fundamentales, se ha discutido ampliamente si la política feminista necesita una teoría del Estado y cuál es su papel en las desigualdades de género. Sin embargo, nuestro propósito aquí no es realizar una genealogía de esta inquietud por el Estado, ni un compendio de aquello debates históricos. ${ }^{2}$ Más bien, nos interesa relanzar la cuestión del Estado asumiendo una posición feminista en la teoría, indicando en la estela althusseriana que se trata de "un campo siempre ya ocupado" (Romé, 2021, p. 47, las cursivas son de la autora).

Hay feminismos que tienden a identificar el Estado con un modo de organización patriarcal y colonial cómplice de los proyectos de desposesión, las lógicas extractivas y los dispositivos financieros. En tanto “comando centralmente planificado” (Gago, 2019, p. 125), el Estado operaría como un mecanismo de cooptación de cualquier lucha emancipatoria. Desde esta mirada, cuando el Estado no aparece como un ente totalizante y centralizador, se presenta como un Otro que solo responde a las demandas contra las distintas violencias (de género, institucionales, económicas, sociales, étnicas, políticas, etc.) que atraviesan nuestros cuerpos en calidad de víctimas a ser reparadas. Sin desconocer la articulación entre capitalismo, patriarcado y colonialismo, que ha signado la historia de los Estados en América Latina, la transformación de estos tópicos requiere un cuestionamiento de aquellos imaginarios en torno al Estado. Sobre todo, si se tiene en cuenta que el neoliberalismo en su embestida desdemocratizadora contra la soberanía popular y cualquier forma de "Estado social" (Brown, 2020), también ha contribuido a sedimentar un sentido común fuertemente antiestatista. La tendencia autonomista de los feminismos latinoamericanos ha obstaculizado su encuentro con las experiencias nacionales-populares latinoamericanas de las últimas décadas (Cadahia, 2019). Quizás sea momento, entonces, de acompañar la crítica del funcionamiento que tiene en tal o cual coyuntura un Estado concreto de una práctica teórica más rica conceptualmente que nos permita trasladar los diversos modos de vida que sostenemos desde las luchas feministas hacia nuestras múltiples perspectivas teóricas. Solo que esto exige transformar radicalmente nuestra perspectiva de abordaje.

Hoy más que nunca, en medio de esta pandemia, es indispensable una teoría feminista del Estado para repensar las formas, las funciones y las modalidades que pueden adoptar los Estados en esta situación tan excepcional. Porque en este momento los Estados son las únicas instancias sociales que tienen la capacidad de coordinación y centralización, como los recursos que se necesitan para salvar vidas. Claro que no todos los Estados tienen la misma capacidad, así como tampoco sus respuestas institucionales encarnan las mismas orientaciones ético-políticas, veremos. Pero no podemos desconocer que la pandemia ha revalorizado el papel de los Estados en todo el mundo, incluso si esta revalorización no siempre es positiva. Ahora bien, a pesar de la centralidad que han adoptado los Estados en los debates actuales, las reflexiones a propósito de su rol en el nuevo escenario mundial no van más allá de una reposición del viejo Estado de bienestar o de un escenario futurológico apocalíptico de un Estado de control total. Este empobrecimiento de los imaginarios sobre el futuro, del que el Estado no es sino un síntoma (sea bajo la modalidad keynesiana, sea con el estilo 1984), es lo que una teoría feminista puede desarticular. Algunas de las dificultades que existen actualmente para pensar el Estado en esta situación excepcional tienen que ver asimismo con el método de abordaje teórico seguido. Por eso, antes que proyectar figuras 
imaginarias reconocidas, tenemos que replantearnos el modo mismo de pensar, de conocer y hacer teoría.

¿A qué llamamos "teoría feminista”? Aquí está el nudo de la cuestión: entendemos al feminismo (o más bien, a los feminismos) realmente anudado(s) con otras teorías materialistas. El feminismo es también un materialismo, pero no porque dialogue con el marxismo o con el materialismo histórico (Hennessy e Ingraham, 1997; García Bravo y Concheiro Bórquez, 2021), sino en la medida en que coincide en tres cuestiones básicas con una filosofía materialista, que va más allá del marxismo: a) en un modo de conocer que contempla la corporalidad, los afectos y lo estrictamente singular; b) en un modo de ser que se orienta hacia la felicidad y la vida verdadera, sin comparación o exclusión de los otros; y c) en un modo de constituirse a sí mismo en función de prácticas concretas, entrenamiento corporal y espiritual al mismo tiempo, que permite ampliar el horizonte de posibilidades e imaginar otros futuros. Es decir, ontología, epistemología, ética y política anudadas materialmente, en simultaneidad, son algo de lo que el feminismo (sin distinguir sus tendencias contradictorias para apostar a su desarrollo) no debería prescindir y que su misma práctica contribuye a sostener (Farrán, 2021). Pues, en el predominio exclusivo de la lógica fálica y el idealismo filosófico que es su correlato, por el contrario: 1) los modos de conocer y argumentar siguen la sucesión rígida y el encadenamiento reglado, la división característica y partición de esferas del conocimiento; 2) su modo de ser también es excluyente y privilegia ciertas disposiciones o tonalidades afectivas por sobre otras; 3) mientras que las prácticas de constitución de sí suelen ser ignoradas o caer en modelos sacrificiales. En definitiva, el feminismo materialista se inscribe en la lógica lacaniana del no-Todo, mientras que la lógica fálica exclusiva y el idealismo lo hacen en la lógica del Todo. Asimismo, el Estado suele ser pensado desde matrices de totalización, ligadas al excepcionalismo y la lógica soberana; pero también podemos pensarlo desde el no-Todo y las singularidades sin excepción.

Se trata de deslindar y asumir una tendencia filosófica que no es pura, sino que se debate de continuo con el idealismo -como decía Althusser- en el cual siempre se puede recaer (por la fijación de principios ajenos a lo real). No obstante, el materialismo como posición y ethos consiste justamente en pensar siempre a partir de lo real concreto, del caso singular y al mismo tiempo de los procesos complejos, diversos y entrelazados en que se desenvuelven los fenómenos, acontecimientos e inercias estructurales indagadas, cualquiera sea el nivel considerado. Pensar en la coyuntura, en la contemporaneidad, con esa distancia mínima que permite captarla en su sobredeterminación compleja y en implicación con ella (no es la moda o la agenda lo que se persigue, sino la eternidad del instante).

No se es materialista simplemente por la referencia (i. e., las cosas mismas), sino por el modo de trabajo que se adopta. De allí la importancia nodal del método, no como receta o protocolo de procedimientos estipulados, sino como modo de invención ajustado al caso. Un método que no parte de ciertas reglas o procedimientos preestablecidos, sino que resulta inseparable del saber en el que se realiza (Farrán, 2018a). Desde un pensamiento materialista consecuente el Estado, el Mercado, la Sociedad o la Comunidad, formulados así en mayúsculas, no son sino entelequias abstractas, generalidades vacuas. Por eso, preferimos pensar más bien en aparatos de Estado, dispositivos y prácticas concretas en las que se trazan distintas orientaciones: reproductivas, transformadoras o destructivas, que no se dan puras, sino que se solicitan mutuamente entre sí. Pensar el Estado implica entonces pensar en simultaneidad las racionalidades políticas, las ideologías y las orientaciones éticas con las que se enlaza. De tal forma que es preciso enlazar diferentes tradiciones y teorías en sus puntos de intersección o solapamiento: teorías materialistas 
del Estado, del sujeto, del método, de la ética, de la imaginación, de la racionalidad política y de la ideología, que se encuentran en la afirmación de una ontología inmanente, relacional o procesual, que atiende al modo de constitución de los seres en su complejidad y singularidad inherentes, no según patrones sustanciales fijos, jerarquizaciones o divisiones rígidas. Pero esta ontología no puede desconocer que, históricamente, hay estructuras de emplazamiento que tienen su peso e inercia específicas. Tampoco se trata de sostener la ontología como una serie de presupuestos establecidos a priori, definidos de una vez y para siempre, sino de una práctica discursiva y existencial concreta en la que el pensamiento se ejercita de continuo para reencontrar la procesualidad relacional y la multiplicidad efectiva en cada situación óntica.

El pensamiento material consiste en buena medida, por lo tanto, en evitar caer en las dicotomías típicas: reformismo-revolución, ética-política, plebeyismo-estatismo, individuo-colectivo, etc. Podemos encontrar puntos de indistinción y anudamiento entre las tradiciones populistas y plebeyas, incluido el feminismo, en lugar de oponerlas burdamente. Así como desde cierto punto de vista se puede afirmar que el populismo opera una suerte de normalización de la potencia plebeya, también hay que poder ver que el plebeyismo y el feminismo operan una suerte de politización de la potencia estatal. Son tendencias que se entrecruzan y no realidades o identidades fijas; tendencias que pujan, se potencian y retroalimentan. Hay una virtud en el ordenamiento y la organización de los recursos (humanos, ambientales, culturales), así como también la hay en el desborde y la reinvención de nuevas formas institucionales; hay que asumir la inmanencia radical de los procesos de transformación e implicarse en el punto de cruce donde uno se sienta autorizado a intervenir desde el deseo que potencia y no desde el moralismo superyoico que condena, segrega o culpabiliza. Esta última es la modalidad operatoria por excelencia que despliegan el patriarcado y todas las formas de dominación.

La crítica materialista no es masiva ni meramente opositiva, no subsume todo juicio a una lógica, dispositivo o lenguaje clave (por ejemplo, el derecho o la economía); toma en consideración cada práctica, cada material, cada relación social y nivel en juego; ante todo, atiende a la sobredeterminación concreta del acto o enunciado. Finalmente, su resolución no es un juicio de valor, sino un acto de corte que busca transformar las coordenadas en función del deseo y lo que aumenta la potencia de obrar. Esto es, una crítica que apunta sobre todo a la transformación del sujeto en relación con la verdad que lo constituye. La crítica por tanto no es el criticismo, posición idealista por excelencia. Algo clave de la crítica materialista es en cambio su sentido de la oportunidad o, en términos althusserianos, su "eficacia específica". Muchas veces no nos entendemos, incluso entre quienes tenemos cierta afinidad ideológica, porque queremos hacer notar algo en un medio que no condice con ello y con recursos que tampoco corresponden; fallamos el nivel de análisis, el destinatario, el efecto deseado o las posibilidades de incidencia, etc. A veces, por ejemplo, se desestiman las redes o los artículos o los comunicados o las acciones de gobierno o las asambleas y resoluciones, porque no se sostiene su irreductibilidad y la tarea de hacer las traducciones correspondientes al caso, de un plano a otro. No tiene ningún sentido hacer una "crítica masiva al Estado", como decía Foucault (2007), pues habría que concentrarse más bien en los modos específicos de gobernar las conductas, incluyéndose uno mismo allí: las posibilidades de pensar y escribir de otro modo, según el medio, el lugar, los otros, etc.

En ese sentido, no está de más insistir en que pensar el Estado no significa asumir una "perspectiva estadocéntrica" (Gago, 2019) o la ilusión estatista que encuentra en él la solución a todos los males de la sociedad, como si la sola intervención estatal pudiera resolver las contradicciones, los problemas y las dificultades que caracterizan a las sociedades contemporáneas. 
Entre el centralismo democrático-republicano y el voluntarismo de las luchas "desde abajo", existen múltiples vías y formas de composición de distintas tradiciones políticas. En este momento en que (al igual que otros a lo largo de la historia argentina y latinoamericana) se hace evidente la irreductibilidad del Estado, de lo que se trata es de considerar qué formas de Estado y de gobierno pueden mejorar las condiciones de vida de las mayorías y, a la vez, favorecer procesos de democratización en todos los niveles y en el presente, no en un futuro lejano o en una comunidad utópica. De esta manera, colocar al Estado como objeto específico del pensamiento materialista, abordarlo en el conjunto de las contradicciones que lo constituyen en tanto tal, ya apunta a la posibilidad misma de su transformación; solo que corresponde a la práctica política hacerlo.

\section{EL ESTADO EN INMANENCIA: FUERZAS, AFECTOS Y ESTRUCTURAS}

A grandes rasgos, tres operaciones teóricas suelen aparecer cuando se intenta abordar al Estado. Una de estas consiste en su trascendentalización, es decir, en ubicar al Estado en una posición de exterioridad con respecto a los procesos sociales y como "fundamento" de estos. ${ }^{3}$ Si en términos metafísicos la trascendentalización supone plantear un principio separado y anterior del que se desprende todo lo que existe, en términos políticos entender al Estado en trascendencia implica pensarlo como un principio de ordenamiento social anterior, separado de la sociedad que gobierna. O como una entidad que se sostiene por sí misma y mantiene una relación exterior con la "sociedad civil". También con las clases sociales, los movimientos sociales, las luchas populares, los demás estados en el sistema mundial, etc. Otra operación correlativa consiste en su instrumentalización, esto es, en pensar al Estado como un instrumento al servicio exclusivo de determinados sectores sociales: los "hombres", las clases dominantes o ciertos grupos económicos, por ejemplo. En función de esto, el Estado no tendría ningún tipo de autonomía ni entidad más allá de aquellos grupos que lo capturan y utilizan para promover sus propios intereses. Finalmente, otra operación radica en lo que podemos llamar su fijación o identificación monolítica, que significa entender al Estado como "bloque monolítico sin fisuras" (Poulantzas, 2005, p. 159), siempre idéntico a sí mismo, estable e impermeable a las luchas y procesos sociales. Por supuesto, las tres operaciones están anudadas: solo si se considera al Estado como una sustancia separada y anterior a la sociedad sobre la que reina, es posible entenderlo como un bloque estático que puede ser cooptado enteramente por un grupo para ponerlo a disposición de sus intereses específicos sin ningún tipo de mediación. ${ }^{4}$

La teoría feminista del Estado que aquí proponemos parte, en cambio, de asumir su irreductible inmanencia. Es decir, no pensamos al Estado como algo externo a la sociedad que gobierna, sino como la condensación singular de las relaciones de fuerza que la componen. Esta proposición tiene sus raíces en la teoría del Estado de Nicos Poulantzas, que lo define como una relación social o, más bien, como "la condensación material de una relación de fuerzas" (Poulantzas, 2005, p. 154, las cursivas son del autor), y en la perspectiva (meta)ontológica de Alain Badiou, que lo concibe como la "cuenta de las partes de una situación" (meta-estructura irreductible a cualquier situación o presentación) (Badiou, 1999). Nos interesa traer a colación tanto a Poulantzas como a Badiou para componer y enriquecer sus teorías con una tradición materialista más amplia, que nos lleva desde la reconstrucción del marxismo por Althusser hasta la ontología de los afectos de Spinoza (Farrán, 2016; Gorriti, 2020), y que permite inscribir al Estado en un "estructuralismo de las pasiones" (Lordon, 2018) que lo conecta con los significantes y con las luchas que sostenemos desde los feminismos. 
Entender el Estado en inmanencia significa, ante todo, pensarlo en continuidad con el orden social en el que existe. Si el Estado es una entre otras instancias sociales, es también en un conjunto social determinado que le da su especificidad. De acuerdo con Althusser y Poulantzas, este orden social es un todo estructurado complejo constituido por la conjunción de diferentes estructuras y prácticas (no siendo las primeras otra cosa que una cristalización estabilizada por el tiempo de prácticas): económicas, ideológicas, políticas, teóricas, etc. Estas instancias tienen autonomía relativa (son irreductibles entre sí), una lógica específica y una eficacia propia, es decir que producen efectos dispares en el "todo social" que conforman en conjunto (Althusser, 2004). Lo social no aparece, entonces, como una totalidad uniforme y centralizada, sino como un sistema de instancias sin centro que funcionan de manera conjunta y entrelazada, cuya relación conflictiva las constituye en tanto tales. El concepto clave que propone Althusser para dar cuenta de esta relación en la que el Todo no es más que la relación activa de sus partes, es el de sobredeterminación. La sobredeterminación compleja de las prácticas muestra la especificidad e irreductibilidad de cada una de ellas en el todo social, al mismo tiempo que sus inescindibles relaciones, puesto que solo en medio de estas relaciones se constituye cada práctica en tanto tal. Atender a la sobredeterminación supone, por lo tanto, considerar las relaciones que cada práctica guarda con las demás, así como los medios de producción y los materiales específicos con los que trabaja, sus variaciones y su índice de eficacia o el modo en que cada práctica afecta a las demás y es afectada "en la estructura de conjunto del todo" (Althusser y Balibar, 2006, p. 117).

Las resonancias con la ontología spinozista son evidentes aquí. ${ }^{5}$ Spinoza nos presenta un tipo de causalidad inmanente que apunta, simultáneamente, a la eficacia del Todo sobre sus partes y a la acción de las partes sobre el Todo. En la filosofía de Spinoza, cada cosa que existe en la Naturaleza es un modo finito y singular de la sustancia única e infinita. Y cada uno de estos modos no es en-sí es decir, no es una (la) sustancia-, sino en Dios (o la naturaleza) y con-otros. Dicho de otra manera, cada cosa se define por una potencia de obrar y existir, de perseverar en el ser (el conatus), que está íntimamente afectada por otras y que afecta a su vez a otras. De la misma manera en que no hay para Althusser prácticas puras y cerradas sobre sí mismas, no hay para Spinoza modos finitos o conatus que no estén ya afectados o contaminados por otros modos, que no aumenten o disminuyan su potencia en función de sus encuentros con los demás. Y esto nos entrega, igualmente, otra clave para pensar la inmanencia del Estado. Porque aquello que la ontología spinozista nos enseña es que la base de la sociedad son los afectos (tristeza, alegría y deseo) y que todas las prácticas (económicas, políticas, ideológicas, éticas, teóricas, etc.) se orientan en función de ellos.

Si las estructuras institucionales son cristalizaciones de prácticas y las prácticas se orientan de acuerdo con los afectos, entonces las propias estructuras condensan y favorecen ciertos regímenes afectivos. Como sostiene Fréderic Lordon (2018), es a través de la mediación de los afectos que las estructuras determinan, aunque no completamente ni de manera unívoca, a los individuos a comportarse de tales o cuales formas. Pero si los individuos adoptan esos comportamientos es, a la vez, en tanto han deseado comportarse de esa manera al existir en medio de aquellas estructuras ${ }^{6}$. La potencia de obrar y existir de los individuos (o el conatus) "sólo toma forma adhiriéndose a las estructuras sociales, a las formas institucionales y a las relaciones sociales que le ofrecen sus condiciones concretas de ejercicio y, de este modo, configuran sus investimentos posibles determinándola a algo" (Lordon, 2018, p. 108). Por lo tanto, no solo hay fuerzas motrices en las estructuras -lejos de cualquier acusación de "olvido de la historia"-, sino que estas se sostienen a través de un balance afectivo concreto en el que coexisten afecciones alegres y tristes; así como 
hay tendencias reproductoras del orden existente, también hay tendencias transformadoras y destructivas que se solicitan mutuamente y no se dan jamás de forma pura.

Ahora bien, volviendo al Estado, este ocupa una posición paradójica en el todo social (Jessop, 2015). Pues, aunque se trata de una estructura particular entre otras, tiene un rol de cohesión y organización del todo social que permite darle cierta unidad al conjunto de las estructuras que lo componen. Esta capacidad del Estado de resguardar la unidad de lo social le da un poder que parece situarlo por encima de este orden. En palabras de Friedrich Engels: "ese poder, salido de la sociedad, pero que se sitúa por encima de ella y le es cada vez más extraño es el Estado" (citado de Poulantzas, 1970, p. 49). No obstante, esta separación y extrañeza del Estado solamente son aparentes porque su propio poder viene dado por las fuerzas sociales cuyas prácticas se sedimentan o cristalizan con el tiempo en sus estructuras. Poulantzas explica que el Estado condensa y materializa en sus aparatos e instituciones el balance de fuerzas de clase que define a una sociedad determinada. Así, no hay Estado neutral, ni éste es un instrumento al servicio de los intereses de tal o cual clase. Antes bien, el Estado es tanto un conjunto de estructuras como un campo estratégico de continuas negociaciones, alianzas, rupturas y tensiones entre fuerzas de clase en el que la dominación política no se encuentra nunca permanentemente o por completo establecida. Las formas que adoptan y las funciones que cumplen los aparatos y estructuras del Estado están sobredeterminadas por la lucha de clase a la vez que esta última se encuentra sobredeterminada por las estructuras políticas, económicas e ideológicas del todo social.

Así, el Estado es inmanente en la medida en que no es un principio que anteceda al orden social que gobierna, ni es exterior a él. La ilusión de separación aparece cuando dejamos de pensar nuestra implicación en ese conjunto del que somos parte y en el que nos formamos como sujetos a través de una diversidad de prácticas e instancias. Ahí donde Poulantzas descubre alianzas y conflictos de clase, Spinoza (1986) observa los afectos comunes que un orden institucional logra establecer para determinar a los individuos a actuar de ciertas maneras. Si llevamos la noción relacional del Estado de Poulantzas más allá de su límite de clases, descubrimos este balance afectivo que sostiene la relación de fuerzas sociales del que está conformado el Estado. Cada capa del orden social es un compuesto de tejidos y cada tejido una red de relaciones, siempre singular (un complejo afectivo). Poulantzas rastrea en los efectos de atomización de los agentes de la producción (la separación imaginaria de sus relaciones de clase) y de representación de la unidad social la manera en que el Estado logra aparecer como representante del "interés general" del pueblo-nación y ocultar su carácter de clase. Al separar a los individuos de sus relaciones de clase y reunificarlos y reconocerlos como sujetos de derecho de una misma comunidad política, el Estado se posiciona como el lugar de lo universal, ajeno a las contradicciones de clase. En este proceso, la ideología (o el modo en que los agentes viven sus condiciones de existencia) tiene el rol fundamental de ocultar las contradicciones reales y de "reconstruir, en un plano imaginario, un discurso relativamente coherente que sirva de horizonte a lo 'vivido' de los agentes", es decir, de darle forma a sus representaciones según las relaciones reales para insertarlas en la unidad del orden social (Poulantzas, 1970, p. 265). A su vez, el Estado opera reagrupando las partes de una situación histórico-social que ya han sido contadas por la estructura económica, y esa segunda cuenta, como teoriza Badiou, normalmente opera de manera constructivista: basada en un lenguaje que no admite lo indiscernible o genérico, sino lo que puede ser discernido y caracterizado según los saberes disponibles de la situación y no las verdades en su potencia infinita. Pero esa no es la única orientación que puede tomar un Estado singular concreto; además de las orientaciones trascendentalista y la constructivista, existe una orientación genérica. 
La ontología de Spinoza nos muestra otra cara de este proceso de externalización imaginaria del Estado (que, como insistimos desde las luchas feministas, no está atravesado solamente por demarcaciones de clase, sino también de género, raciales, étnicas, etc.). Lordon lo reconstruye de esta manera: las estructuras sociales invisten en objetos particulares la energía libre y sin objeto del conatus individuado. Librado de esta determinación institucional, el conatus es "un querer para sí mismo sin ningún principio de contención ni de moderación a priori" (Lordon, 2018, p. 170). Se entiende, por consiguiente, la necesidad de inscribir esta potencia en relaciones institucionales que permitan la coexistencia armoniosa de los individuos. El paso del estado de naturaleza al estado civil ha sido un tema recurrente en la filosofía política. Se suele citar a Hobbes a este respecto, pero Spinoza da una explicación de este paso que no se queda en el simple renunciamiento de los individuos al derecho natural o en la coacción de la potencia que supone. Por el contrario, la filosofía de Spinoza supone que el esfuerzo de cada individuo para perseverar en la existencia solamente puede ser perseguido junto a otros, a través de instituciones que aumenten esta potencia. Spinoza insiste en la necesidad de un Estado que proteja ${ }^{7}$, no tanto por temor a la fragilidad y vulnerabilidad de la vida, "sino por las posibilidades inauditas que genera una organización humana capaz de componer y potenciar el deseo de perseverar en el ser" (Farrán, 2020, p. 33). ${ }^{8}$

Lo que el Estado, al igual que otras instituciones sociales, estabiliza temporariamente es una relación de poder que establece con los individuos mantenidos en su imperio. Como "el imperium de la institución no es otra cosa que el afecto común que ella logra producir para determinar a los individuos a vivir según su norma -y que Spinoza llama obsequium, afecto de reconocimiento de la autoridad institucional y de obediencia a sus mandatos-" (Lordon, 2018, p. 119), el poder del Estado sobre los sujetos no es independiente del poder que estos le otorgan. No se trata de una lógica de representación y delegación del poder, sino de una continuidad ontológica: este poder que el Estado ostenta sobre aquellos que gobierna cristaliza la potencia común de los "súbditos". El concepto que da cuenta de esta comprensión inmanente del poder del Estado es el de potencia de la multitud. Es esta la que permite explicar la capacidad del Estado de afectar a gran escala, de producir un orden relativamente homogéneo de afectos y normalizar ciertos comportamientos. La potencia de la multitud apunta al modo en que los individuos se afectan mutuamente y pasan de ser "singularidades" a constituir "colectividades" (que a su vez sostienen y son singularidades). Para Lordon, se trata de una "composición polarizada de las potencias individuales tal que, al sobrepasar por la composición misma todas las potencias por las cuales está constituida, es un poder para afectar a todos" (2018, p. 225). Por lo tanto, el poder del Estado no tiene otro origen que esta composición de la potencia de aquellos sobre quienes gobierna. No hay una renuncia y una delegación de los sujetos hacia un Estado preexistente, ni una comunidad utópica exterior al Estado. No es que los individuos, como sujetos preexistentes al campo de poder en el que operan, actúen sobre unas estructuras ya constituidas en tanto tales. Lo que hay, más bien, es un tipo de causalidad estructural (o de causa inmanente) en la que las fuerzas sociales -no los individuos en sentido estricto- afectan las estructuras en la medida en que están constituidas por ellas.

Surge aquí uno de los aspectos más significativos de la noción inmanente del Estado. Si la base de la autoridad política radica en las composiciones afectivas y en las relaciones de fuerza que definen a una sociedad determinada, entonces su conservación depende de estas. Dicho de otra manera, la ruptura con el orden existente sostenido por el Estado viene de su interior, no desde fuera. El Estado mantiene en un "equilibrio inestable de compromisos" (Poulantzas, 1970, p. 244, las cursivas son del autor) ese balance de fuerzas y afectos que lo caracteriza. Del movimiento de estas fuerzas 
depende la conservación o la destrucción de las relaciones de poder que se condensan en el Estado. La inmanencia del Estado muestra que el reverso de su imponente poder es la fragilidad del tejido social y de las oscilaciones de los afectos. Basta que ese balance se incline masivamente hacia otro lado para que se deshaga el entramado afectivo que regía. Sin embargo, Poulantzas nos previene de la deriva ingenua de este planteo: como el Estado es la condensación material de una relación de fuerzas (y afectos, cabe agregar), tiene una inercia y una estabilidad propias que hacen que aquellos movimientos no se traduzcan de manera directa e inmediata en una ruptura del orden existente. Es decir, no alcanza con un voluntarismo de las fuerzas y afectos para cambiar las cosas. Son necesarios largos procesos de luchas dentro de las estructuras del Estado y fuera de ellas (aunque no exteriores a su campo estratégico) para transformarlas.

\section{DE LA LÓGICA DE LA GUBERNAMENTALIDAD NEOLIBERAL A LA LÓGICA GUBERNAMENTAL DE LOS CUIDADOS: POR UN “ESTADO CUIDADOR”}

Entender la especificidad de cada lucha, los afectos que ellas producen distintamente, es crucial en este largo proceso. De entrada, habría que asumir la infinitud constitutiva de los procesos genéricos de verdad, como les llama Badiou. Las perspectivas poultantziana-althusseriana y lordiana-spinozana son necesarias, pero no suficientes para alcanzar ese entendimiento de la complejidad y singularidad de los procesos. Una teoría feminista del Estado exige repensar también la lógica de los cuidados en su estricta singularidad. Pensar la institucionalidad de manera inmanente a los procesos sociales, a las relaciones de fuerza y complejos afectivos entonces es crucial, pero hay que dar un paso más. Lordon no llega a articular en su perspectiva la última parte de la Ética de Spinoza, referida al tercer género de conocimiento y la beatitud: pensamiento de cada cosa o modo singular en su esencia. Lo que consideramos crucial, más ahora que nunca en que la ética de los cuidados está a la orden del día. Para esto nos servimos también del último Foucault, quien permite pensar conjuntamente la ética y la política, el gobierno de sí y de los otros: no hay oposición entre ellas, como no la hay entre estructura y sujeto, o entre individual y colectivo, o entre singular y genérico; lo que hay es una relación topológica de borde unilátero. Habría que pasar entonces, siguiendo el título de Lordon, de La sociedad de los afectos: por un estructuralismo de las pasiones a escribir, en clave feminista, La sociedad de los cuidados: por un postestructuralismo de las acciones. Activar los afectos es siempre una cuestión de modalización singular de la potencia común que nos constituye, cualquiera sea el nivel de integración institucional o estructural en que opere y se transforme el sujeto.

Muchas veces por comodidad decimos "las mujeres", planteando un universal y respondiendo a una descripción esencialista que infiere de rasgos secundarios la condición política, hablante y sexuada. Es cierto, no obstante, que las violencias suelen ejercidas en función de ese nivel superficial; pero si nos introducimos en las lógicas institucionales, hay que ver caso por caso cómo se posiciona cada sujeto: solo en situaciones concretas y sostenidas se verifica quién es mujer. De hecho, puede haber seres autopercibidos mujeres que ejerzan igual violencia a compañeras y compañeros. El asunto no es idealizar a las mujeres en general (que no existen) ni condenar a las instituciones per se (que pueden funcionar de distintos modos), sino analizar cómo y qué instituciones están abiertas a feminizarse en sus formas y procedimientos, a saber: admitir las singularidades y diferencias irreductibles sin aplastarlas ni excluirlas. 
Entre la diversidad de prácticas que se despliegan e inscriben en la tópica social compleja, las prácticas de sí nos permiten entender la transversalidad y sobredeterminación que implica un cambio de paradigma radical, suscitado en gran medida por el feminismo: de la lógica de gubernamentalidad neoliberal a la lógica gubernamental de los cuidados. Lo primero a hacer notar es que los cuidados, así entendidos, remiten a prácticas de gobierno de sí y de los otros que no se basan en modelos familiaristas, maternales o paternales, sino en prácticas ascéticas y éticas reflexivas. Tampoco se trata de excluir la importancia del cuidado familiar, educacional o sanitario, tal como se practican en nuestras sociedades actuales, pero sí de comenzar a modularlos y enriquecerlos a partir del conocimiento crítico de la formación y constitución del sujeto en términos filosóficos más rigurosos. De ahí la importancia de los estudios foucaultianos sobre las prácticas de sí antiguas (Foucault, 2002), como el estudio de la filosofía de Spinoza en el punto que enlaza afectividad y conocimiento de manera ineludible.

El problema es que la mayoría de las lecturas contemporáneas de Foucault no pasan del concepto de biopolítica y el neoliberalismo, del estudio de los mecanismos de poder y el control de los cuerpos, etc. Incluso algunos, en el súmmum de la ignorancia, llegan a ver allí una reivindicación en lugar de una crítica del neoliberalismo. Muy pocos -fuera de los especialistas- exploran el último Foucault y lo ponen al uso del entendimiento crítico del presente. ${ }^{9}$ Pero resulta clave este último Foucault para situarnos ante la pandemia y en relación con los cambios necesarios para sostener una teoría feminista del Estado ligado a los cuidados. No solo porque nos permite hacer una crítica inmanente al modo de subjetivación neoliberal (el empresario de sí), a través de la reposición de prácticas de sí antiguas (sumamente actuales), sino porque nos permite vincular la constitución de sí con las prácticas de gobierno y los dispositivos de saber, interrogando unas realidades a través de las otras, produciendo desplazamientos y reformulaciones consecuentes en torno a la verdad en juego. En definitiva, un ejercicio de la crítica materialista en inmanencia, sin presuposición de exterioridades puras o inducción a posiciones denegatorias autodestructivas. Nuestra hipótesis es que la dificultad para captar la enseñanza de este último Foucault y su uso (más acá del regocijo del especialista), reside en las torpes formas de subjetivación que aun dominan la enseñanza y la transmisión (secundarias, terciarias o universitarias). ${ }^{10}$ Cuando no se implica al sujeto en los modos de escucha, lectura y escritura de manera práctica, semejante desafección respecto a la verdad tiene consecuencias muy graves. Hoy lo estamos viendo por todos lados, de manera sintomática, pero es momento de cambiar.

Hace tiempo ensayamos nuevas modulaciones de las prácticas de sí, contra todo dogma colectivista o individualista. El cuidado de sí es cuidado del otro, como también es cuidado del mundo, cuidado de las palabras, cuidado de las cosas, cuidado de la naturaleza, cuidado de los saberes, cuidado de las instituciones, cuidado de las multitudes, cuidado de la economía, cuidado de la anomalía, cuidado de la política, cuidado de los sueños, cuidado esencialmente del deseo y la potencia de perseverar en el ser. El cuidado apunta a todos los modos posibles de incrementar nuestra potencia de obrar, de sentir, de pensar, por composiciones virtuosas junto a otros, aunque sea a la distancia (ahora que priman los dispositivos virtuales). Reinventar todos los dispositivos, tecnológicos y estatales, es posible y hasta necesario si nos dejamos orientar por la lógica del cuidado y la potencia que nos constituye en común. Para ello es necesario producir una reforma del entendimiento que atraviese todos los niveles y dispositivos en juego y conduzca también a un cambio afectivo crucial. La formación subjetiva y el método de pensamiento se enlazan ineluctablemente a la teoría feminista del Estado. 
El desafío para las prácticas éticas y políticas de los cuidados, desde un enfoque filosófico materialista, consiste en sostener su especificidad al mismo tiempo que se transfieren y recrean sus procedimientos en distintas instancias y prácticas de la formación social, incluso a nivel del Estado, sus distintos estamentos de gobierno y el uso de las nuevas tecnologías. Pues pensamos que las políticas de los cuidados tienen que incluir también el uso de los dispositivos digitales y virtuales, por ejemplo, como plantean algunas/os aceleracionistas (Avanessian y Reis, 2017) o desde el xenofeminismo (Hester, 2018). Si no inventamos una nueva forma de lazo social, una erótica que convoque el deseo y ensaye un modo amistoso de relacionarnos a la distancia, usando las redes sociales virtuales, va a ser muy difícil recomponernos del aislamiento. No avalamos los diagnósticos o discursos grandilocuentes que quieren hacer pasar por lucidez el pesimismo catastrófico y la melancolía incurables, a través del rechazo masivo de la técnica y los dispositivos en uso; acaso eran lujos para momentos de circulación masiva e incertidumbre epistemológica. Tampoco podemos seguir alimentando la estupidez o estulticia promovida por todos los medios. Hoy, las certezas angustiantes exigen actos que efectivamente las desplacen hacia una tópica social donde el deseo sea posible, cualquiera sea el medio o los recursos a disposición; pues una ética materialista de los cuidados parte ineluctablemente de lo que hay, para componer más y mejor.

Las luchas feministas históricas, de algún modo reivindicadas y amplificadas por las necesidades de la situación actual, con la importancia nodal que toman las políticas de los cuidados, nos abren horizontes de futuro para pensar una sociedad mejor, en tanto están habilitadas para situarse crítica y cuidadosamente en el presente. Para ello será necesario no obstante mucha entereza y fortaleza, más que agudeza reivindicativa, así como el cultivo de un ánimo templado que invista la propia potencia de actuar y la transfiera a los otros. Como decía Spinoza (2006), la fortaleza es una actitud afectiva que requiere de firmeza para conservar el ser y generosidad para hacerlo en composición con otros. Lo sabemos muy bien filosóficamente: el paradigma de gobierno neoliberal se revela impotente ante la necesidad de composición de singularidades irreductibles en un marco común de reparto y redistribución de recursos a todo nivel. El cuidado, por supuesto, implica toda nuestra naturaleza extendida y entendida en su conjunción heterogénea y problemática: el deseo individual, los derechos sociales, las nuevas tecnologías y el Estado pensado en su complejidad relacional. Todas instancias indisociables las unas de las otras, entrelazadas, pero no homogéneas.

Por otra parte, las luchas feministas y las luchas populares, así como las diversas luchas contra la dominación, la segregación, la destrucción y la impotencia, pueden encontrar en este instante de peligro cada vez más vasos comunicantes si atienden al nudo irreductible en que nos encontramos. Es decir, no solo para aliarse contra lo peor, en términos de cadenas equivalenciales formales, sino para investir su propia potencia de actuar y transferir sus saberes en múltiples instancias, habilitando formas materiales de reinvención del lazo social. Un lazo social que atienda especialmente al modo en que nos cuidamos los unos a los otros de manera alternada (cuidar de sí es cuidar también a los otros) y nos diferenciamos conjuntamente; no en función de la competencia o el mérito, sino en la ineludible tarea de devenir sujetos morales de nuestras acciones, en tanto entendemos que lo que hacemos repercute necesariamente en la trama social compleja de la que formamos parte. La articulación entre ética y política se muestra más necesaria que nunca en esta coyuntura, cuando las diferencias potencian y no son algo meramente tolerable.

Para que las luchas se anuden en inmanencia, sin renunciar a las diferencias singulares que nos potencian, necesitamos entender cómo se incrementa la potencia de actuar puntualmente y cómo se activan los afectos alegres: un verdadero conocimiento de lo que nos causa singularmente, en cada caso, a implicarnos con la situación. El deseo aquí no puede ser algo secundario o 
antojadizo, pues es lo que nos moviliza en verdad en un instante de peligro, y no el mero instinto de supervivencia. Por tanto, una nueva erótica de los cuerpos políticos resulta indispensable, más acá de cualquier voluntarismo o "deber ser" enunciado desde posiciones morales. Una ética del bien decir, del bien escuchar, del bien escribir y, en definitiva, del bien estar, no es un adorno superfluo para momentos de sosiego, sino la fórmula más ajustada a la materia insólita que nos toca tratar: lo real. Enfocarnos en lo que aumenta nuestra potencia de actuar y captar lo singular, en lugar de sostener posiciones reactivas o recelosas. El Estado de Bienestar, entonces, no puede ser solo una figura político-económica o histórica a reponer, sino el modo mismo en que nos pensamos como sujetos ético-políticos en cualquier nivel de las prácticas.

En una entrevista televisiva reciente ${ }^{11}$, Rita Segato dijo que le parecía crucial disputar las narrativas que se construyan a la salida de la situación pandémica (si es que "salimos", añadió); incluso habló de un "Estado materno". Nosotros preferimos hablar de "Estado de los cuidados", antes que de "Estado maternal", porque el cuidado excede las funciones de reproducción y maternaje. El cuidado incluso puede ser concebido de modo ascético y firme, como lo muestran las "prácticas de sí" estoicas que estudiaba Foucault. En todo caso, lo distintivo de la cultura del "cuidado de sí" es una reflexividad crítica y una puesta a prueba constante de lo sensible: evaluación de lo que aumenta o disminuye nuestra potencia. Consideramos que una orientación materialista del Estado, que vincule todas las instancias y prácticas posibles (salud, educación, trabajo, policía, etc.), desde la óptica rigurosa del cuidado, resulta indispensable para afrontar este delicado momento y lo que de aquí se siga.

Llama la atención que en la actualidad se hable de la necesidad de un "Estado fuerte", por un lado, y de asumir o sostener las necesarias "fragilidades" o "vulnerabilidades", por otro. Sea para conjurar, prevenir o rechazar ese "supuesto estado", nuevamente se ponen en juego las tramposas dicotomías del pensamiento de izquierda. Si hoy en Argentina podemos hablar de un "Estado cuidador" es porque antes hubo un "Estado reparador" que supo, además, escuchar y dar lugar a un sujeto político de los derechos humanos que anudó -y reanuda una y otra vez- Memoria, Verdad y Justicia, en respuesta al traumático "terrorismo de Estado" (y también, no olvidemos, porque hubo en 2001 un desfondamiento radical del Estado que obligó su refundación anudada a ese sujeto). No son meros significantes vacíos ni significa que cualquier gobierno pueda dar ese uso singular al Estado (aunque sí pueda su signatura ejemplar orientar a otros). Son marcas que constituyen el tejido de nuestra dolorosa historia y lo que habilita también una activación de la potencia colectiva ${ }^{12}$.

Apostemos, entonces, a profundizar un cambio materialista en la organización del Estado, ligado ahora a la primacía de los cuidados y los aparatos ideológicos que lo encarnan en su faz transformadora: ciencia, salud, familia, educación, etc. En lugar de un paradigma "securitario" del Estado, como el que ha prevalecido, un paradigma "cuidaritario". Para que la tendencia materialista se profundice, atravesando el Estado, hay que entender que la lógica de transferencia y contaminación que ejerce un aparato sobre los otros no puede ser homogénea; tiene que haber traducciones y transformaciones inventivas que inspiren las prácticas desarrolladas en distintas instancias, atendiendo siempre al lugar del más débil en cada relación de poder -para invertirla y que no se convierta en estado de dominación. El primer obstáculo epistemológico para captar estas transformaciones y profundizarlas, pues son tendencias y no fines, proviene de la espontaneidad ideológica homogeneizante con que los practicantes se suelen representar otras prácticas y niveles. Un político materialista entiende las diferencias y desfasajes de tiempos y lugares: su conexión 
inmanente. Tenemos que alcanzar ese entendimiento espacial, esta inteligencia material del tiempo, dentro de nuestras limitaciones actuales.

\section{CONCLUSIONES}

Retomando lo que sosteníamos al comienzo, podemos proponer entonces, siguiendo el interés manifiesto de algunas autoras feministas por Spinoza (Sharp, 2019), que la vía ejemplar para objetar el predominio de la lógica fálica en su conjunto (totalizador y homogeneizante), lógica de la medida y el cálculo continuos que alimenta el neoliberalismo, resulta de pensar spinozianamente la ética y la política a través del "tercer género de conocimiento" (Spinoza, 2006). Modo de pensar y ser eminentemente práctico que se puede entender mejor si se lo aborda desde la lógica del anudamiento borromeo (Farrán, 2018b). El tercer género de conocimiento es en realidad bastante simple de entender si se lo piensa nodalmente; solo que exige un arduo cambio de perspectiva, que no es solo gnoseológica, sino, en esencia, ética y afectiva. Pues se trata de conocer no en función de la imaginación espontánea que define el primer género (por cosas dichas u oídas, asociaciones, etc.), o las nociones comunes que definen el segundo género (por enlaces significantes, universales, inducciones, deducciones, etc.), sino en función de las cosas singulares y sus causas próximas, reales y materiales (por abducciones, invenciones, nominaciones, etc.). Esa disposición ético-afectiva de atender cada vez a la cosa singular que se considera, sin reducirla a lo que se imagina o a las nociones comunes prevalentes, comprendiendo la compleja materialidad de los procesos en que se constituye, es ardua pero no imposible de practicar; hay modos concretos de ejercitarse en ello. Sobre todo, se requiere una suerte de conversión subjetiva y afectiva de base que es radical. Un modo de gozar que no puede ser en detrimento de los otros, esto es, cultivar una forma de vida o de asumir la vida que no se basa en la exclusión de -o comparación con- el otro.

Como dice Hasana Sharp, la concepción anti-aislacionista que plantea Spinoza (a la cual habría que traducir positivamente más bien como una "ontología relacional") ${ }^{13}$ permite entender y actuar sobre lo singular de manera oportuna, atendiendo también a la ineludible dimensión afectiva:

Aun si es imposible conocer el orden completo y la conexión de las causas que explican un solo fenómeno, la perspectiva anti-aislacionista de Spinoza libera nuestra percepción. Spinoza afirma que el dejar de explicar las cosas, especialmente las acciones humanas, por un tipo de espontaneidad original propia de los individuos "contribuye a la vida social, en cuanto que enseña a no odiar a nadie, ni despreciar, ni burlarse, ni irritarse, ni envidiar a nadie" (Ética II, p49s). Esto comparte algo con el argumento feminista y anti-colonial de que la comprensión de la experiencia individual como parte de un patrón causal libera a los oprimidos del odio y el auto-castigo. Además de liberar la energía destructiva, las nuevas explicaciones revelan nuevos lugares de intervención y nuevas prácticas de resistencia transformadora (Sharp, 2019, s.p.).

Así, podemos entender no solo cómo "lo personal es político", según el dictum feminista habitual, sino que lo afectivo es índice de un conocimiento verdadero. Pero esto implica a su vez una operación sobre sí mismo. Incluso habría que preguntarse si no hay un narcisismo primario en juego que es irreductible, amor de sí que el sujeto debe alcanzar o reencontrar, atravesando espejos y valoraciones sociales de toda índole, para poder vincularse realmente con los otros, en función de la verdadera potencia y sabiduría que nos constituye. No sujetos sacrificiales y culpógenos que gozan solo de la falta de sí, o sujetos envidiosos y vanidosos que gozan solo ante la falta del otro; una transformación real de la sociedad en su conjunto requiere de sujetos íntegros en su formación: ética, política y epistémica al mismo tiempo. 
Contra las tecnologías del poder neoliberal, que no se basan en la represión directa sino en estimular y excitar nuestra potencia para destruirnos mejor (Dorlin, 2018), necesitamos recuperar las prácticas de sí de la sabiduría antigua, modificarlas en función de nuestros modos de ser y conocer actuales; investirnos libidinalmente y gozar en función de ejercicios materiales de apropiación de los saberes e inversión de las relaciones de poder concretas, situación por situación, etc. Y todo eso hacerlo de manera simultánea y entrelazada, pensando y atendiendo a las múltiples dimensiones implicadas; es la única forma de objetar la lógica fálica que reproduce el orden neoliberal imperante, atravesando diversas ideologías e identificaciones. Esa es la tarea conjunta del materialismo filosófico y del feminismo que buscan exceder la lógica del Todo, afirmar el noTodo y el anudamiento entre heterogeneidades irreductibles, no solo en lo que respecta a los modos de ser, sino de conocer y enlazarse afectivamente.

Hemos dispuesto algunos elementos teóricos y prácticos complejos, entrelazados, que nos permiten esbozar el movimiento hacia una teoría feminista del Estado, cuyo nudo pase por la lógica afectiva de los cuidados. Para ello fue necesario en un primer momento desandar las dicotomías típicas que se presentan en algunos debates feministas, presentando una perspectiva materialista compleja de la tópica social, sus instancias y prácticas; luego introdujimos la dimensión afectiva ineludible para pensar los movimientos y orientaciones inherentes a la complejidad social, las instituciones y el Estado; por último, acentuamos la importancia de la reflexividad ética para entender la lógica de los cuidados desde la singularidad. El desarrollo de ejercicios concretos de subjetivación que permitan incorporarse a verdades genéricas no excluyentes ni segregativas, puede afirmarse y extenderse desde el Estado, sin que eso inhiba las iniciativas que puedan surgir de otras organizaciones y movimientos. Al contrario, el punto nodal es considerar que, en este momento de emergencia sanitaria y social a toda escala, el lugar del Estado como cuidador puede ayudar a repensar y mejorar el modo en que nos relacionamos con nosotros mismos. Recuperar la dimensión ética de la política, en tanto ejercicios concretos de subjetivación, ligados al conocimiento afectivo de lo singular, es lo que una propuesta feminista y materialista puede aportar a un pensamiento del Estado en situación, caso por caso. Por supuesto que esta orientación queda abierta a nuevos desarrollos y profundizaciones que no se agotan en las referencias y conceptos esbozados, pero son los puntos nodales que hemos deseado explicitar. Eso es asumir una posición materialista en el campo teórico.

\section{Bibliografía}

Althusser, Louis (2004). La revolución teórica de Marx. Buenos Aires: Siglo XXII.

Althusser, Louis y Balibar, Étienne (2006). Para leer El Capital. México: Siglo XXI.

Arruzza, Cinzia (2015). Las sin parte. Matrimonios y divorcios entre feminismo y marxismo. Barcelona: Sylone.

Arruzza, Cinzia y Cirillo, Lidia (2018). Dos siglos de feminismos. Los ejemplos más significativos, los problemas más actuales... Barcelona: Sylone.

Avanessian, Armen y Reis, Mauro (comps.) (2017). Aceleracionismo. Estrategias para una transición hacia el postcapitalismo, Buenos Aires: Caja Negra.

Badiou, Alain (1999). El ser y el acontecimiento. Buenos Aires: Manantial.

Butler, Judith (1991). Disorderly woman. Transition, (53), 86-95. doi:10.2307/2935175

Butler, Judith (2001). Mecanismos psíquicos del poder. Teorías sobre la sujeción. Madrid: Ediciones Cátedra. Butler, Judith (2009). Dar cuenta de sí mismo. Violencia ética y responsabilidad. Buenos Aires: Amorrortu. 
Brown, Wendy (1992). Finding the Man in the State. Feminist Studies, 18(1), 7-34.

Brown, Wendy (2020). En las ruinas del neoliberalismo. El ascenso de las políticas antidemocráticas en Occidente. Buenos Aires: Tinta Limón, Futuro Anterior y Traficantes de sueños.

Cadahia, Luciana (2017). Mediaciones de lo sensible. Hacia una economía crítica de los dispositivos. Buenos Aires: Fondo de Cultura Económica.

Cadahia, Luciana (2019). El círculo mágico del Estado. Populismo, feminismo y antagonismo. Madrid: Lengua de trapo.

Dorlin, Elsa (2018). Defenderse. Una filosofía de la violencia. Buenos Aires: Hekht.

Farrán, Roque (2016). Nodal. Método, estado, sujeto. Buenos Aires: La Cebra-Palinodia.

Farrán, Roque (2018a). Nodaléctica. Un ejercicio de pensamiento materialista. Adrogué: La Cebra.

Farrán, Roque (2018b). “Spinoza posfundacional: ¿Puede el nudo borromeo lacaniano ayudarnos a pensar la causalidad inmanente, la contingencia de la necesidad?". En Ana Leila Jabase et al.(comps.), Spinoza Maledictus: Spinoza Treceavo Coloquio. Córdoba: Universidad Nacional de Córdoba, pp. 300-310.

Farrán, Roque (2020). Leer, meditar, escribir. La práctica de la filosofía en pandemia. Adrogué: La Cebra.

Farrán, Roque (2021). La razón de los afectos. Populismo, feminismo, psicoanálisis. Buenos Aires: Prometeo.

Federici, Silvia (2020). Reencantar el mundo. El feminismo y la política de los comunes. Madrid: Traficantes de sueños.

Foucault, Michel (2002). La hermenéutica del sujeto. Curso en el Collège de France (1981-1982), Buenos Aires: Fondo de Cultura Económica.

Foucault, Michel (2007). Nacimiento de la biopolítica. Curso del Collège de France (1978-1979). Buenos Aires: Fondo de Cultura Económica.

Fuentes Megías, Fernando (2020). El filósofo, el psicagogo y el maestro. Filosofía y educación en Pierre Hadot y Michel Foucault. Buenos Aires: Miño y Dávila.

Fraser, Nancy (2015). Fortunas del feminismo. Madrid: Traficantes de sueños.

Fraser, Nancy y Butler, Judith (2016). ¿Reconocimiento o redistribución? Un debate entre marxismo y feminismo. Madrid: New Left Review en español y Traficantes de sueños.

Gago, Verónica (2019). La potencia feminista. O el deseo de cambiarlo todo. Buenos Aires: Tinta Limón.

García Bravo, María Haydée y Concheiro Bórquez, María Elvira (coords.) (2021). El ejercicio del pensar: marxismos y feminismos, 10. Buenos Aires: CLACSO.

Gorriti, Jacinta (2020). Nicos Poulantzas. Una teoría materialista del Estado. Santiago de Chile: Doble Ciencia.

Hennesy, Rosemary y Ingraham, Chrys (eds.) (1997). Materialist Feminism. A Reader in Class, Difference, and Women's Lives. Nueva York: Routledge.

Hester, Helen (2018). Xenofeminismo. Tecnologías de género y políticas de reproducción, Buenos Aires: Caja Negra.

Jessop, Robert (2015). “El Estado y el poder”, Utopía y praxis latinoamericana, 19 (66), 19-35.

Lordon, Frédéric (2018). La sociedad de los afectos. Por un estructuralismo de las pasiones. Buenos Aires: Adriana Hidalgo.

Mackinnon, Catharine (1995). Hacia una teoría feminista del Estado. Madrid: Ediciones Cátedra.

Poulantzas, Nicos (1970). Poder político y clases sociales en el Estado capitalista. México: Siglo XXI.

Poulantzas, Nicos (2005). Estado, Poder y Socialismo. México: Siglo XXI.

Romé, Natalia (2020). Althusser con Spinoza. Hacia una ciencia revolucionaria. Nuevo itinerario, 16(1), 143-175. 
Romé, Natalia (2021). Notas para un feminismo transindividual. En García Bravo, María Haydée y Concheiro Bórquez, María Elvira (coord..), El ejercicio del pensar: marxismos y feminismos, 10, Buenos Aires: CLACSO, 45-59.

Sharp, Hasana (1 de junio de 2019). “¿Por qué Spinoza y el feminismo?”, Reflexiones marginales, 51. https:/ 22018.reflexionesmarginales.com/por-que-spinoza-y-el-feminismo/

Spinoza, Baruch (1986). Tratado político. Madrid: Alianza Editorial.

Spinoza, Baruch (2006). Ética. Demostrada según el orden geométrico. Madrid: Alianza Editorial.

Notas

1 Retomamos el título del libro de Catharine MacKinnon, Towards a Feminist Theory of the State [1989]. Sin embargo, no compartimos su enfoque en ningún sentido y por eso no nos explayaremos en él siquiera para diferenciarnos, pues el marco es completamente diferente. Al igual que Carole Pateman, pero más próxima al marxismo, MacKinnon es representante de una corriente feminista radical que tuvo amplias repercusiones en la academia norteamericana de los años 80 y 90. En su libro, MacKinnon sostiene que "el feminismo no tiene una teoría del Estado" que aborde el vínculo específico de "la mujer" y el Estado (1995, p. 277). Es decir, que analice el Estado "desde el punto de vista de las mujeres" para entender cómo el poder de los hombres sobre las mujeres se organiza como poder de Estado (1995, p. 228). De acuerdo con la feminista norteamericana, el poder estatal se identifica con el poder masculino y, al mismo tiempo, ese poder del Estado no es otra cosa que el poder de la ley. Así, ante un derecho masculino, excluyente y limitante, MacKinnon propone elaborar una jurisprudencia feminista. Es claro, entonces, el desplazamiento desde el problema del Estado a la cuestión de la jurisprudencia. Desde nuestra perspectiva, elaborar una teoría feminista del Estado supone ir más allá de una mirada jurídico-política. Además, coincidimos con las críticas que teóricas como Judith Butler (1991) y Wendy Brown (1992) han realizado a la posición de MacKinnon. Puntualmente, la manera en que "hombre" y "mujer" denotan en su libro posiciones fijas dentro de una relación de opresión que no tiene en cuenta la interseccionalidad de las formas de opresión (Butler, 1991); y la reducción del Estado a una sola forma de poder, que pierde de vista la dimensión multifacética y a menudo incoherente de las diferentes prácticas, discursos y reglas que coexisten en su terreno (Brown, 1992).

$2 \quad$ Para un acercamiento a estos debates, ver: Brown, 1992; MacKinnon, 1995; Arruzza, 2015; Fraser, 2015; Fraser y Butler, 2016; Arruzza y Cirillo, 2018; Gago, 2019; Federici, 2020.

3 Badiou explica esta necesaria ilusión de trascendentalización del Estado (que va de Aristóteles a Marx) al pensarlo en términos ontológico-matemáticos, como la cuenta de las partes (o sub-múltiples) de una situación histórico-social. Véase el capítulo 9 de El ser y el acontecimiento, "El estado de la situación histórico-social". "Engels y Lenin han remarcado el carácter separado del Estado y han mostrado además -lo que es verdad- que la coerción se corresponde con la separación. De ahí que para ellos la esencia del Estado sea su maquinaria burocrática y militar, esto es -si se lo examina desde la sola perspectiva de la situación inmediata y de sus términos- la visibilidad estructural de su exceso respecto de la inmediatez social, su carácter de monstruosa excrecencia" (1999, p. 127).

$4 \quad$ La comprensión del Estado de MacKinnon (1995) es un ejemplo de este tipo de teorización, en la medida en que el Estado aparece identificado completamente con el poder masculino, más o menos invariante en su constitución y efectos sobre las mujeres.

5 Para un análisis de la herencia spinozista que Althusser lee sintomáticamente en Marx, ver: Romé, 2020.

6 Judith Butler $(2001,2009)$ señala un punto importante a este respecto. Como las normas sociales proporcionan el punto de referencia de nuestros actos, aunque no de una manera determinista, la identidad social que estas ofrecen garantiza la continuidad en la propia existencia. En la medida en que aquellas normas establecen el marco en que ciertas formaciones subjetivas son pensables, vivibles y deseables, existe un vínculo apasionado e involuntario con ellas.

7 Como escribe en la Ética (IV, prop. LXXIII): “El hombre que se guía por la razón es más libre en el Estado, donde vive según leyes que obligan a todos, que en la soledad, donde sólo se obedece a sí mismo”. 
8 Luciana Cadahia (2017) rastrea en el proyecto inconcluso de Schiller de una constitución estética un tipo de mediación jurídico-política que toma en cuenta la dimensión de los afectos en las decisiones políticas y en las leyes propuestas desde el Estado.

9 Por citar solo dos intervenciones recientes: https://www.nodal.am/2020/03/notas-sobre-coronavirus-y-sobre-c uidado-de-si-y-de-los-otros-un-cambio-real/; https://www.ieccs.es/post/el-blackout-de-la-critica

10 Un excelente trabajo que repone los usos posibles de Foucault (y Hadot) en el campo de la educación es el de Fernando Fuentes Megías (2020).

11 https://www.youtube.com/watch?v=L5JjUAW82is

12 Véase la breve y hermosa entrevista a Fabiana Rousseaux que hizo Alejandra Dandan en El cohete a la luna: $\underline{\mathrm{h}}$ ttps://www.elcohetealaluna.com/los-espejos/

13 O una “ontología transindividual”, como propone Natalia Romé (2020) leyendo a Étienne Balibar. 